\title{
Bernoulli equation and flow over a mountain
}

\author{
Wen-Yih Sun ${ }^{1,2,3^{*}}$ and Oliver M. Sun ${ }^{4,5}$
}

\begin{abstract}
The Bernoulli equation is applied to an air parcel which originates at a low level at the inflow region, climbs adiabatically over a mountain with an increase in velocity, then descends on the lee side and forms a strong downslope wind. The parcel departs from hydrostatic equilibrium during its vertical motion. The air parcel can be noticeably cooler than the temperature calculated from adiabatic lapse rate, which allows part of enthalpy to be converted to kinetic energy and produces a stronger wind at mountain peak and a severe downslope wind on the lee side. It was found that the hydrostatic assumption tends to suppress the conversion from enthalpy to kinetic energy. It is also shown that the Froude number defined in the atmosphere is equal to the ratio of kinetic energy to the potential energy, same as in Boussinesq fluid. But in the atmosphere, the Froude number cannot be used to determine whether a parcel can move over a mountain or not, unless the vertical motion is weak and the system is near hydrostatic equilibrium. Numerical simulations confirm that except in highly turbulent areas, the potential temperature and Bernoulli function are almost conserved along the streamline, as well as the change of kinetic energy comes from the change of enthalpy instead of potential energy.
\end{abstract}

Keywords: Adiabatic; Bernoulli equation; Downslope wind; Enthalpy; Froude number; Hydrostatic-adiabatic process

\section{Background}

Severe downslope winds on the lee sides of mountains have been observed frequently around the world. They may trigger dust storms in the Taklimakan Desert and Gobi Desert (Sun et al., 2013a, b). Several hypotheses have also been proposed to explain these winds, including: (a) hydraulic jump: if the mountain height exceeds a certain threshold, a strong wind can develop along the lee when a subcritical flow transitions to a supercritical flow (Long 1953; Peltier and Clark 1979; Smith 1985; Durran 1986; Baines 1995; Doyle et al. 2000; Lin 2007). The hydraulic jump was originally derived from shallow-water equations; (b) superposition of upward- and downward-propagating waves: Klemp and Lilly (1975) suggested that strong downslope winds occur when the atmosphere has a multilayer structure that produces an optimal superposition of upward- and downward-propagating waves; (c) wave breaking and enhancement of downslope winds by the energy trapped by the wave-breaking region in the upper layer and/or wave-induced critical layer (Clark and Peltier 1977,

\footnotetext{
* Correspondence: wysun@purdue.edu

'Department of Earth, Atmospheric and Planetary Sciences, Purdue

University, 550 Stadium Mall Drive, West Lafayette, IN 47907-2051, USA

${ }^{2}$ Department of Atmospheric Sciences, National Central University, Chung-Li,

Tao-yuan 320, Taiwan

Full list of author information is available at the end of the article
}

1984; Peltier and Clark 1979; Smith 1989; Aihara and Hirasawa 1988; Lin 2007). Because the numerical simulations with a nonslip surface could not simulate the longlasting severe windstorms observed in Boulder from the conventional theories, Sun (2013) has proposed a new theory: (d) geostrophic adjustment of the geostrophic-unbalanced upper-level jet introducing a convergence in the upper layer and enhancing the downslope wind. Sun's numerical simulations reproduced a long-lasting, strong downslope wind $\left(\sim 50 \mathrm{~m} \mathrm{~s}^{-1}\right)$ on the lee side over a nonslip surface. More detailed discussions are referred to Sun (2013).

The Bernoulli equation in a two-layer fluid is a popular explanation for the formation of hydraulic jump. The Bernoulli equation has also been used to study the development of blocking flows as well as aerodynamic and hydrodynamic problems (Clancy 1975). Long (1953, denoted as L53 hereafter) presented a mathematically linear equation governing steady mountain waves of large amplitude in an incompressible fluid (Smith 1985, denoted as S85 hereafter). S85 also used an incompressible Bernoulli equation to calculate the severe downslope wind in the lee of a mountain. Although the assumption of incompressibility and hydrostatic equilibrium is useful for obtaining analytical solutions, nonhydrostatic, nonlinear numerical models in fully compressible fluid show that dynamic

\section{实}


pressure can be significant for realistic flows moving over a mountain; however, these effects are ignored in the models of L53, S85, and others. The numerical simulations also confirm that, over a free-slip surface, the Bernoulli equation holds well for an isentropic flow over a mountain before it reaches high-turbulence regions on the lee side. However, the simulated density is not a constant along a constant Bernoulli line.

According to the Bernoulli equation, the energy needed for a parcel to climb over a mountain can come from both kinetic energy and enthalpy. Therefore, the conventional Froude number, i.e., $\mathrm{Fr}=U / N h$ where $U$ is the basic flow speed, $N$ the Brunt-Väisälä frequency, and $h$ the mountain height, may not be appropriate to represent this energy conversion in a stratified, compressible fluid flow. Through Bernoulli equation, we prove that the conventional Froude number does represent the ratio between kinetic energy and potential energy in a compressible fluid.

It is noted that the Bernoulli equation is only exact for an inviscid, steady flow. It is also noted that a small area of returning flow near the surface on the windward side may propagate upwind with time. In highly turbulent regions on the lee side, the flow may become unsteady too. Our nonlinear numerical model requires eddy viscosity and weak smoothing to ensure numerical stability in simulating flow over a high mountain. However, the impacts of smoothing and viscosity are found to be insignificant except in turbulent regions or near the surface when a nonslip surface is used. Numerical results show that conservations of Bernoulli function (which is related to the total energy of an air parcel and is defined as $B$ in Methods) and potential temperature hold quite well before the flow encounters highly turbulent regions on the lee side of the mountain. In nonslip surface cases, above the surface frictional layer, the simulated $B$, potential temperature, and streamlines are near-parallel, and Bernoulli function and potential temperature conservation also hold quite well.

\section{Methods}

The Bernoulli equation derived from the Navier-Stokes equations consists of the kinetic energy, potential energy, and enthalpy. The analytical solutions also reveal that when an air parcel moves over a mountain, the change of kinetic energy comes from the change of enthalpy instead of from the potential energy, which invalids the popular theory of hydraulic jump based on the conversion between potential energy and kinetic energy. The detailed deviations also show that the conventional Froude number cannot be applied to estimate the mountain height a flow can climb over because it ignores the change of enthalpy.

Numerical simulations obtained from National Taiwan University-Purdue University nonhydrostatic model show the detailed structure of the flow passing a mountain, including an increase of velocity near the mountain peak and a strong downslope wind on the lee side where the temperature and pressure are relatively lower than the surroundings. They also show that potential temperature, streamline, and Bernoulli function almost remain constant following the trajectory of an air parcel, but wind, pressure, and density changes significantly.

\section{Results and discussion}

\section{Basic equations and analytic solutions}

The 2D nonhydrostatic equations for the dry, compressible atmosphere can be written as:

$$
\begin{aligned}
& \frac{\partial u}{\partial t}+u \frac{\partial u}{\partial x}+w \frac{\partial u}{\partial z}=-\frac{1}{\rho} \frac{\partial p}{\partial x}+D_{u} \\
& \frac{\partial w}{\partial t}+u \frac{\partial w}{\partial x}+w \frac{\partial w}{\partial z}=-\frac{1}{\rho} \frac{\partial p}{\partial z}-g+D_{w} \\
& \frac{\partial \theta}{\partial t}+u \frac{\partial \theta}{\partial x}+w \frac{\partial \theta}{\partial z}=D_{\theta} \\
& \frac{\partial \rho}{\partial t}=-\left(\frac{\partial \rho u}{\partial x}+\frac{\partial \rho w}{\partial z}\right) \\
& p=\rho R T \\
& \theta=T\left(\frac{p_{o}}{p}\right)^{R / c_{p}}
\end{aligned}
$$

where $u$ and $w$ are the $x$ - and $z$-components of the wind; $p$ is the pressure; $\theta$ is the potential temperature; $T$ is the temperature; $\rho$ is the density; $R$ is the gas constant; $c_{p}$ is the specific heat at constant pressure; $D_{u}$ and $D_{w}$ are the momentum diffusions along the $x$ - and $z$-directions; and $D_{\theta}$ is the heat diffusion. Equations (1)-(2) can be combined and written compactly in vector form

$$
\frac{\partial \mathbf{V}}{\partial t}+\nabla\left(\frac{\mathbf{V} \cdot \mathbf{V}}{2}\right)+(\nabla \times \mathbf{V}) \times \mathbf{V}-\frac{\nabla p}{\rho}-\mathbf{g}+\mathbf{D}
$$

where $\mathbf{V}=(u, w)$. If we define the displacement by $d \boldsymbol{r}=(d x, d z)=\mathbf{V} d t$ and integrate (7) from the initial state $i$ to the final state $f$ :

$$
\int_{i}^{f}\left(\frac{\partial \mathbf{V}}{\partial t}+\nabla\left(\frac{\mathbf{V} \cdot \mathbf{V}}{2}\right)+(\nabla \times \mathbf{V}) \times \mathbf{V}-\frac{\nabla p}{\rho}+\mathbf{g}-\mathbf{D}\right) \cdot d \mathbf{r}=0
$$

Because $(\nabla \times \mathbf{V}) \times \mathbf{V}$ is orthogonal to $d \mathbf{r},(\nabla \times \mathbf{V}) \times$ $\mathbf{V} \cdot d \mathbf{r}=0$.

Thus, for a steady, inviscid flow, the Bernoulli equation becomes:

$$
\left.\left(\frac{\mathbf{V} \cdot \mathbf{V}}{2}\right)\right|_{i} ^{f}+\int_{i}^{f} \frac{d p}{\rho}+\left.g z\right|_{i} ^{f}=0 .
$$


Because in adiabatic process $c_{p} d T-\frac{d p}{\rho}=0$, Eq. (9a) becomes:

$$
\begin{aligned}
\left(\frac{\mathbf{V} \cdot \mathbf{V}}{2}\right)_{f}+c_{p} T_{f}+g z_{f} & =\left(\frac{\mathbf{V} \cdot \mathbf{V}}{2}\right)_{i}+c_{p} T_{i}+g z_{i} \\
& =B(\text { Bernoulli function })
\end{aligned}
$$

Equation (9a) has been discussed in Clancy (1975). Bernoulli function remains constant along a streamline. From Eq. (9b), we can obtain

$$
d\left[\left(\frac{\mathbf{V} \cdot \mathbf{V}}{2}\right)+c_{p} T+g z\right]=d(\mathrm{KE})+c_{p} d T+g d z=0
$$

where $c_{p} d T=d h$, and $h$ (specific enthalpy) $=c_{v} T+p / \rho$, where $c_{v}$ is the specific heat at constant volume. Hence, Bernoulli function may be considered as the total energy, i.e., the summation of the kinetic energy, enthalpy, and potential energy (PE).

We also define

$$
B_{L} \equiv\left(\frac{\mathbf{V} \cdot \mathbf{V}}{2}\right)+\frac{p}{\rho_{\mathrm{i}}(z, x=0)}+g z
$$

and

$$
B_{s} \equiv\left(\frac{\mathbf{V} \cdot \mathbf{V}}{2}\right)+\frac{p}{\rho_{c}}+g z
$$

where the density $\rho$ is replaced by the initial value $\rho_{i}(z$, $x=0)$ in Eq. (11a) following L53, and $\rho_{c}=1 \mathrm{~kg} \mathrm{~m}^{-3}$ in Eq. (11b) according to S85. The simulated Bernoulli function, potential temperature, and streamlines generated from a nonlinear numerical model are almost parallel before reaching high-turbulence regions or near a nonslip surface. This implies that the flow is nearly adiabatic, inviscid, and steady in the areas we are interested. The contours of $B_{\mathrm{L}}$ of Eq. (11a) will be presented as well for comparison in the next section.

Here, we will define a hydrostatic-adiabatic process as an air parcel moves adiabatically from $z_{i}$ to $z_{f}$ and follows the hydrostatic equation (i.e., $d w / d t \sim 0$ ). The change of pressure with height in a hydrostatic-adiabatic process can be derived

$$
d p=-\rho g d z=-\rho_{i}\left(\frac{p}{p_{i}}\right)^{c_{v} / c_{p}} g d z
$$

and

$$
\int_{z_{i}}^{z_{f}} g d z=g\left(z_{f}-z_{i}\right)=g \Delta z=-\frac{p_{i}^{c_{\nu} / c_{p}}}{\rho_{i}} \int_{p_{i}}^{p_{f}} p^{-c_{\nu} / c_{p}} d p=c_{p}\left(T_{i}-T_{f}\right)
$$

The temperature lapse rate is:

$$
\beta=-\frac{T_{i}-T_{f}}{z_{i}-z_{f}}=\frac{g}{c_{p}} \equiv \beta_{\mathrm{ad}}
$$

where $\beta_{\mathrm{ad}} \equiv g / c_{p}$ is the dry adiabatic lapse rate, which is frequently used to calculate the change of the air parcel temperature due to compression/expansion during hydrostatic-adiabatic vertical motions.

Substituting (13) into Eq. (9b), we obtain

$$
\left(\frac{\mathbf{V} \cdot \mathbf{V}}{2}\right)_{f}=\left(\frac{\mathbf{V} \cdot \mathbf{V}}{2}\right)_{i}
$$

which confirms that the kinetic energy remains constant in a hydrostatic-adiabatic process. When a parcel has a large vertical velocity, it usually does not satisfy hydrostatic equilibrium. Hence $T_{f}$ is different from $\left(T_{i}-\beta_{\mathrm{ad}} \Delta z\right)$, Eq. (9b) can be written as:

$$
\begin{aligned}
\left(\frac{\mathbf{V} \cdot \mathbf{V}}{2}\right)_{f}-\left(\frac{\mathbf{V} \cdot \mathbf{V}}{2}\right)_{i} & =c_{p} T_{i}-c_{p} T_{f}+g z_{i}-g z_{f} \\
& =c_{p}\left[T_{i}-\frac{g}{c_{p}}\left(z_{f}-z_{i}\right)\right]-c_{p} T_{f} \\
& =c_{p}\left[T_{i}-\beta_{\mathrm{ad}} \Delta z\right]-c_{p} T_{f} \\
& =c_{p} T_{i, f}^{\mathrm{ad}}-c_{p} T_{f}=c_{p}\left(T_{i, f}^{\mathrm{ad}}-T_{f}\right)
\end{aligned}
$$

where the temperature $T_{i, f}^{\mathrm{ad}}=T_{i}-\beta_{\mathrm{ad}} \Delta z$, is the temperature of an "artificial" air parcel moves from $i$ to $f$ following the adiabatic lapse rate $\beta_{\text {ad }}$ in a hydrostaticadiabatic process, which is different from the simulated temperature $T_{f}$. Equation (16) also implies that the change of kinetic energy comes from the enthalpy difference, $c_{p}\left(T_{i, f}^{\mathrm{ad}}-T_{f}\right)$. The temperatures $T_{f}$ and $T_{i, f}^{\mathrm{ad}}$ will be presented in Table 1 . The adiabatic lapse rate can also be derived from $d \theta / d z=0$ and hydrostatic equation. Hence, adiabatic lapse rate $\beta_{\text {ad }}$ is a warming/cooling rate in a hydrostatic-adiabatic process without changing the kinetic energy (KE) according to Eqs. (15) and (16).

If the hydrostatic equation is applied to Eqs. (11a) and (11b), the KE of the parcel keeps its initial value because

$$
d p=-g p_{c} d z \text { or } d p=-g p_{i} d z
$$

If the pressure of an air parcel automatically adjusts to its environment $(p=\bar{p})$, which is in hydrostatic equilibrium, during adiabatic motion (i.e., the parcel method in 
Table 1 Property of air parcel along constant $B$ at $1 \mathrm{~A}, 1 \mathrm{~B}, \ldots, 4 \mathrm{C}$ : and $T_{i, f}^{\mathrm{ad}}(K)=T_{\mathrm{A}, \mathrm{B}}^{\mathrm{ad}}(K)=T_{\mathrm{A}}-\beta_{\mathrm{ad}} \Delta \mathrm{Z}_{\mathrm{A}, \mathrm{B}}$ at row $1 \mathrm{~B}, T_{i, f}^{\mathrm{ad}}(K)=T_{\mathrm{B}, \mathrm{C}}^{\mathrm{ad}}=T_{\mathrm{B}}-$ $\beta_{\mathrm{ad}} \Delta \mathrm{Z}_{\mathrm{B}, \mathrm{C}}$ at $1 \mathrm{C}, T_{i, f}^{\mathrm{ad}}(K)=T_{\mathrm{A}^{*}, B^{*}}^{\text {ad }}=T_{\mathrm{A}^{*}}-\beta_{\mathrm{ad}} \Delta \mathrm{Z}_{\mathrm{A}^{*}, B^{*}} 1 \mathrm{~B}^{*}$, etc., for cases $1-4$ at different locations

\begin{tabular}{|c|c|c|c|c|c|c|c|c|c|c|c|c|}
\hline $\begin{array}{l}\text { Case + } \\
\text { location }\end{array}$ & $x(\mathrm{~km})$ & $z(\mathrm{~m})$ & $p(\mathrm{hPa})$ & $\theta(\mathrm{K})$ & $T(K)$ & $B\left(\mathrm{~m}^{2} \mathrm{~s}^{-2}\right)$ & $U\left(\mathrm{~m} \mathrm{~s}^{-1}\right)$ & $T_{i, f}^{\mathrm{ad}}(K)=T_{i}-\beta_{\mathrm{ad}} \Delta Z_{i, f}$ & $\rho\left(\mathrm{kgm}^{-3}\right)$ & $\begin{array}{l}\text { Kinetic energy } \\
\left(\mathrm{m}^{2} \mathrm{~s}^{-2}\right)\end{array}$ & $\begin{array}{r}c_{p}\left(T_{i, f}^{\text {ad }}-T\right) \\
\left(\mathrm{m}^{\mathrm{z}} \mathrm{s}^{-2}\right)\end{array}$ & $\begin{array}{l}\mathrm{KE}_{f}-\mathrm{KE}, \\
\left(\mathrm{m}^{2} \mathrm{~s}^{-2}\right)\end{array}$ \\
\hline $1 \mathrm{~A}$ & 160 & 1099. & 748.659 & 291.1 & 268.01 & 280,000 & 11.24 & & 0.9733 & 63.12 & & \\
\hline 1B & 320 & 2391. & 628.278 & 291.1 & 254.91 & 280,000 & 31.89 & 255.40 & 0.8588 & 508.9 & 487.9 & 445.7 \\
\hline $1 C$ & 348 & 378.0 & 795.373 & 290.7 & 272.30 & 280,000 & 74.44 & 274.56 & 1.0178 & 2771. & 2272. & 2263. \\
\hline 1D & 347 & 1087. & 730.587 & 325.2 & 297.29 & 309,930 & 35.90 & & 0.8563 & 645.9 & & \\
\hline $1 A^{*}$ & 160 & 253.9 & 832.548 & 286.9 & 272.24 & 276,007 & 10.39 & & 1.0656 & 54.00 & & \\
\hline $1 B^{*}$ & 320 & 2061. & 656.594 & 286.9 & 254.36 & 276,007 & 24.41 & 254.60 & 0.8994 & 298.13 & 234.9 & 244.1 \\
\hline $2 \mathrm{~A}$ & 160 & 1123. & 744.034 & 291.3 & 267.67 & 279,890 & 4.037 & & 0.9685 & 8.154 & & \\
\hline $2 B$ & 320 & 2227. & 641.966 & 291.3 & 256.65 & 279,890 & 22.94 & 256.90 & 0.8715 & 262.3 & 250. & 254.2 \\
\hline $2 C$ & 340 & 562.3 & 776.768 & 291.3 & 271.01 & 279,890 & 65.61 & 272.90 & 0.9987 & 2155. & 1898. & 1892. \\
\hline $2 A^{*}$ & 160 & 582.9 & 796.686 & 289.3 & 271.10 & 278,039 & 2.183 & & 1.0239 & 2.393 & & \\
\hline $2 B^{*}$ & 320 & 2061. & 656.197 & 289.3 & 256.52 & 278,039 & 18.22 & 256.67 & 0.8913 & 166.1 & 155.6 & 163.7 \\
\hline $3 \mathrm{~A}$ & 160 & 531.3 & 798.692 & 287.4 & 269.55 & 276,000 & 8.159 & & 1.0325 & 33.28 & & \\
\hline 3B & 320 & 2139 & 647.706 & 287.4 & 253.84 & 276,000 & 10.71 & 253.86 & 0.8891 & 57.45 & 17.07 & 24.16 \\
\hline 3C & 353 & 305.1 & 819.443 & 287.4 & 271.52 & 276,000 & 23.23 & 271.74 & 1.0516 & 270.0 & 220.9 & 212.5 \\
\hline $4 \mathrm{~A}$ & 160 & 2870. & 588.768 & 295.7 & 254.15 & 283,597 & 18.55 & & 0.8072 & 172.0 & & \\
\hline 4B & 320 & 3149. & 565.735 & 295.7 & 251.31 & 283,597 & 24.16 & 251.43 & 0.7844 & 292.5 & 119.5 & 120.5 \\
\hline 4C & 332 & 1087 & 737.338 & 295.6 & 270.99 & 283,597 & 38.19 & 271.42 & 0.9481 & 739.2 & 436.7 & 446.7 \\
\hline
\end{tabular}

*indicates parcel trajectory at the inflow region and at mountain peak

meteorology), the parcel temperature from $i$ to $f$ can be calculated by

$$
\begin{aligned}
T_{f} & =T_{i}\left(\frac{p_{f}}{p_{i}}\right)^{R / c_{p}}=T_{i}\left(\frac{\bar{p}_{f}}{p_{i}}\right)^{R / c_{p}}=T_{i}\left[\left(\frac{T_{i}-\bar{\beta} \Delta z}{T_{i}}\right)^{\frac{g}{\beta R}}\right]^{R / c_{p}} \\
& =T_{i}\left(\frac{T_{i}-\bar{\beta} \Delta z}{T_{i}}\right)^{\frac{g}{\beta c_{p}}}
\end{aligned}
$$

where $\Delta z=z_{f}-z_{i}$, and the lapse rate of the environment (with over bar) $\bar{\beta}=-\frac{d \bar{T}}{d z}$, and $d \bar{p}=-\bar{\rho} g d z=-\frac{\bar{p} g d z}{R T}$, or $d$ $\ln \bar{p}=-\frac{g}{R \bar{\beta}} d \ln \left(T_{i}-\bar{\beta} z\right)$. Equation (9b) becomes

$$
\begin{aligned}
\left(\frac{\mathbf{v} \cdot \mathbf{V}}{2}\right)_{i}-\left(\frac{\mathbf{v} \cdot \mathbf{V}}{2}\right)_{f} & =c_{p} T_{i}\left[\left(\frac{T_{i}-\bar{\beta} \Delta z}{T_{i}}\right)^{\frac{g}{\bar{\beta} c_{p}}-1}\right]+g \Delta z \\
& =c_{p} T_{i}\left[\left(1-\frac{\bar{\beta} \Delta z}{T_{i}}\right)^{\frac{g}{\beta c_{p}}}-1\right]+g \Delta z \\
& =c_{p} T_{i}\left\{\left[1-\frac{g}{\bar{\beta} c_{p}} \frac{\bar{\beta} \Delta z}{T_{i}}+\frac{g}{2 \bar{\beta} c_{p}}\left(\frac{g}{\bar{\beta} c_{p}}-1\right)\left(\frac{\bar{\beta} \Delta z}{T_{i}}\right)^{2}-\ldots\right]-1\right\}+g \Delta z \\
& =\frac{c_{p} T_{i g} g}{2 \bar{\beta} c_{p}}\left(\frac{g}{\bar{\beta} c_{p}}-1\right)\left(\frac{\bar{\beta} \Delta z}{T_{i}}\right)^{2}-\ldots=\frac{g}{2}\left(\frac{g}{c_{p}}-\bar{\beta}\right)\left(\frac{\Delta z^{2}}{T_{i}}\right)-\ldots \\
& =\frac{1}{2} \bar{g} \bar{\theta} \frac{d \bar{\theta}}{d z} \Delta z^{2}-\ldots
\end{aligned}
$$

or

$$
\begin{aligned}
\frac{g}{\theta} \frac{d \bar{\theta}}{d z} \Delta z^{2} & =N^{2} \Delta z^{2}=(\mathbf{V} \cdot \mathbf{V})_{i}-(\mathbf{V} \cdot \mathbf{V})_{f} \\
& =2 \mathrm{KE}_{i}-2 \mathrm{KE}_{f}
\end{aligned}
$$

where $N$ is the Brunt-Väisälä frequency.

Equation (19) shows that $2 \mathrm{KE}_{i}-2 \mathrm{KE}_{f}$ can be converted to potential energy $N^{2} \Delta z^{2}$ in a stable atmosphere. Let us define Rat:

$$
\text { Rat }=\frac{\sqrt{2 \mathrm{KE}_{i}-2 \mathrm{KE}_{f}}}{N \Delta z}
$$

If $\mathrm{KE}_{f}=0$ and $\Delta z=$ mountain height $h$, and $2 \mathrm{KE}_{i}=\mathrm{V}$. $\mathbf{V}=U_{i}^{2}$, where $U_{i}$ is the characteristic horizontal velocity at the inflow region, then Rat is identical to the conventional Froude number in meteorology $\mathrm{Fr}=\frac{U_{i}}{N h}$, which is related to the ratio of the kinetic energy change to the potential energy change. The Froude number can also be derived for Boussinesq fluid which 
experiences a hydraulic jump over an obstacle of height $h$ :

$$
\begin{aligned}
\operatorname{Fr} & =\frac{U_{i}}{\sqrt{g^{\prime} h}}=\frac{U_{i}}{\sqrt{g \frac{\theta^{\prime}}{\theta}}}=\frac{U_{i}}{\sqrt{g h \frac{\left(\theta_{i} \frac{d \bar{\theta}}{d z} h\right)-\theta_{i}}{\theta}}} \\
& =\frac{U_{i}}{\sqrt{\frac{g}{\theta} \frac{d \bar{\theta}}{d z} h^{2}}}=\frac{U_{i}}{N h} .
\end{aligned}
$$

where $g^{\prime}=g \theta^{\prime} \mid \theta$ is the reduced gravity and $\bar{\theta}$ is the environmental potential temperature (Baines 1995). It is noted that variation of pressure is not included in the equation of state in Boussinesq fluid, i.e., $\rho^{\prime} / \rho=-\theta^{\prime} / \theta$. The reciprocal of the Froude number $\left(N h / U_{i}\right)$, the nondimensional mountain height, is defined by some meteorologists as a measure of nonlinearity for the continuously stratified flow over topography, instead of Froude number because they argued that $U / N h$ does not represent the ratio of KE and PE as originally defined in the shallow-water fluid for the flow over bottom topography (Lin 2007). On the other hand, (21) confirms that $U / N h$ in a stratified fluid flow does represent the ratio of $\mathrm{KE}$ change and $\mathrm{PE}$ change, as that defined in the shallow water; thus, it is appropriate to call it Froude number.

Equation (20) implies that $U_{f}=\left(2 \mathrm{KE}_{f}\right)^{1 / 2}$ should be less than $U_{i}$ if the air parcel pressure is the same as the surrounding environment, which is in hydrostatic equilibrium.

For a large mountain about $10-\mathrm{km}$ wide $(a \sim 10 \mathrm{~km})$, the mountain waves may be considered as hydrostatic nonrotating waves in linear theory (Gill 1982). The constant phase lines are tilted upstream with height, thus producing a high pressure on the windward slope and a low pressure on the lee slope. The flow decelerates over the windward slope and accelerates over the lee slope. The ground level pressure perturbation and wind vanish at the peak (Gill 1982; Lin 2007). The linearized equations also show that the decrease of the wind on the windward slope is equal to the increase of wind on the lee side. However, they are different from the nonlinear model simulations, in which the increase of wind on the lee slope is much larger than the decrease on the windward slope; the positive wind perturbation extends to the mountain peak, as shown in Durran (1986), Hsu and Sun (2001), etc. But, it was mostly ignored because the conventional theory states that the change of kinetic energy comes from the decrease of potential energy. The patterns of the surface wind and pressure simulated from nonlinear models with $a=10 \mathrm{~km}$ are close to the pattern of the linear, nonhydrostatic waves with $a \sim 1 \mathrm{~km}$ than the hydrostatic waves discussed in Queney (1948), Gill (1982), etc. The increase of $U$ at the peak further reduces the pressure according to Bernoulli equation and results in sucking more air from the lower layer in the upstream. Because the pressure $p_{f}$ is lower than the pressure on the upstream region at the same height, $p_{\text {env }}$, according to (6), we obtain

$$
T_{f}=\theta\left(\frac{p_{f}}{p_{o}}\right)^{R / c_{p}}<T_{\mathrm{env}}=\theta\left(\frac{p_{\mathrm{env}}}{p_{o}}\right)^{R / c_{p}}=T_{i, f}^{\mathrm{ad}}
$$

which is consistent with $\mathrm{KE}_{f}-\mathrm{KE}_{i}=c_{p}\left(T_{i, f}^{\mathrm{ad}}-T_{f}\right)$. More detail will be presented in Results and discussion.

Similarly, the air over the mountain peak descends and accelerates to fill the mass deficit on the lee side created by blocking of the mountain. The wind speed also increases as long as its temperature is cooler than that calculated from adiabatic lapse rate. This has been confirmed by the nonlinear numerical model and will be presented in Results and discussion.

From (5), we may obtain

$$
d \ln p=d \ln \rho+d \ln T, \text { or } \frac{p^{\prime}}{p}=\frac{\rho^{\prime}}{\rho}+\frac{T^{\prime}}{T}
$$

For an adiabatic process, from (6), we obtain

$$
d \ln T=d \ln \theta+\frac{R}{c_{p}} d \ln p, \text { or } \frac{T^{\prime}}{T}=\frac{R}{c_{p}} \frac{p^{\prime}}{p}
$$

If we define $T^{\prime}=T_{f}-T_{i, f}^{\text {ad }}$, we can obtain

$$
\frac{p^{\prime}}{p}=\frac{C_{p}}{R} \frac{T^{\prime}}{T}, \text { and } \frac{\rho^{\prime}}{\rho}=\frac{C_{v}}{R} \frac{T^{\prime}}{T},
$$

where $p^{\prime}=p_{f}-p_{i, f}^{\text {ad }}$ and $\rho^{\prime}=\rho_{f}-\rho_{i, f}^{\text {ad }}$. Hence, if $T^{\prime} \neq 0$, both $p^{\prime}$ and $\rho^{\prime}$ are also different from zero, where $p^{\prime}$ can be interpreted as the dynamic pressure.

\section{Model and numerical simulations}

The National Taiwan University-Purdue University nonhydrostatic model simulations are used for comparison with the analytical results discussed in the previous section. The prognostic variables are potential temperature, velocity, density, turbulent kinetic energy, etc. The detailed equations, physics, parameterizations, and numerical schemes of the model can be found in Hsu and Sun (2001), Sun and Hsu (2005), and Sun (2013). Following Sun et al. (2012, 2013c), we also partially filter the highfrequency acoustic waves to permit a larger time interval while solving for internal gravity waves, since the model uses a time-splitting technique.

The Arakawa $C$ grids are applied in the terrain following the $\sigma$-coordinate, which is defined as:

$$
\sigma=\frac{p_{0}(z)-p_{0}\left(z_{\text {top }}\right)}{p_{0}\left(z_{\text {surface }}\right)-p_{0}\left(z_{\text {top }}\right)},
$$

where $p_{0}$, the pressure in the reference atmosphere, is a function of height. The domain consists of $671 \times 400$ 
grids with a uniform horizontal spatial interval $d x=$ $1 \mathrm{~km}$, and a vertical spatial interval, $d z \approx 75 \mathrm{~m}$, except the first layer above the ground where $d z \approx 25 \mathrm{~m}$. Both free-slip and nonslip surfaces are applied at the ground. In addition to Newtonian damping applied to the upper layers, the top is set at $\approx 30 \mathrm{~km}$, higher than in most models, to reduce spurious reflections from the top boundary, which could produce standing waves and artificially enhance the downslope wind in the numerical model. The variables are fixed at the inflow, $x=0$; and an open boundary is used at the outflow. An idealized mountain with a Witch-of-Agnesi profile $h=h_{m} /\{(x-$ $\left.\left.\left.x_{o}\right) / a\right]^{2}\right\}$ is centered at $x_{o}=320 \mathrm{~km}$ with characteristic width $a=10 \mathrm{~km}$, and height $h_{m}=2 \mathrm{~km}$ (Doyle et al. 2000; Hsu and Sun 2001; Sun and Hsu 2005; and Sun 2013). A free-slip surface is applied to cases $1-3$, and a nonslip surface is applied to case 4 .

Case 1: $U=20 \mathrm{~m} \mathrm{~s}^{-1}$, and $\beta=3.5 \mathrm{~K} \mathrm{~km}^{-1}$ for $z<$ $12 \mathrm{~km}$, and $\beta=0.7 \mathrm{~K} \mathrm{~km}^{-1}$ for $z>12 \mathrm{~km}$ at inflow.

Figure 1a shows the simulated $x$-component wind (indicated by a shaded color), potential temperature $\theta$ (dashed black lines), Bernoulli function $B$ (thick white line), streamlines (thin black line), and pressure $p$ (thin white line) at $t=6 \mathrm{~h}$, when the flows are almost steady except in the highly turbulent regions. Fig. $1 \mathrm{~b}$ is the same as Fig. 1a, except that the shaded colors indicate temperature. The contours of $B, \theta$, and streamlines are almost parallel before flows reach the highly turbulent areas on the lee side, indicating that the flow is nearly steady, adiabatic, and inviscid, even though weak smoothing and a turbulence parameterization are present in the model. The contours of $B$ or $\theta$ are thus approximately trajectories, except inside areas of high turbulence.

We can follow the trajectory of an air parcel along $B=280,000 \mathrm{~m}^{2} \mathrm{~s}^{-2}$, which passes $1 \mathrm{~A}(x=160 \mathrm{~km}, z=$ $1099.14 \mathrm{~m})$ in the upstream region, where $\theta=291.1 \mathrm{~K}$, $T=268.01 \mathrm{~K}, U=11.24 \mathrm{~m} \mathrm{~s}^{-1}$, and $\rho=0.9733 \mathrm{~kg} \mathrm{~m}^{-3} ; 1 \mathrm{~B}$ $(x=320 \mathrm{~km}, z=2391 \mathrm{~m})$ over the mountain peak where $\theta=291.1 \mathrm{~K}, T=254.91 \mathrm{~K}, U=31.89 \mathrm{~m} \mathrm{~s}^{-1}$, and $\rho=$ $0.8588 \mathrm{~kg} \mathrm{~m}^{-3}$; and $1 \mathrm{C}(x=348 \mathrm{~km}, z=378 \mathrm{~m})$ with strong downslope wind, $U=74.44 \mathrm{~m} \mathrm{~s}^{-1}, \theta=290.7 \mathrm{~K}$, $T=272.30 \mathrm{~K}$, and $\rho=1.0178 \mathrm{~kg} \mathrm{~m}^{-3}$, as shown in Table 1 . Fig. 1a, b also shows that, near the mountain top, the wind becomes stronger but the temperature is lower than in the surrounding air. The temperature at $1 \mathrm{C}$ is also cooler than its surroundings.

Rows $1 \mathrm{~A}, 1 \mathrm{~B}$, and $1 \mathrm{C}$ of Table 1 confirm that potential temperature remains almost constant along a constant $B$-function, which implies conservation of $\theta$ and $B$ to be a good approximation, as shown in Fig. 1a, b. The temperature at $1 \mathrm{~B}, T_{1 \mathrm{~B}}=254.91 \mathrm{~K}$ is less than the temperature of a parcel rising from $1 \mathrm{~A}$ to $1 \mathrm{~B}$ following adiabatic lapse rate, $T_{\mathrm{A}, \mathrm{B}}^{\mathrm{ad}}=T_{\mathrm{A}}-\beta_{\mathrm{ad}} \Delta z_{\mathrm{A}, \mathrm{B}}=255.40 \mathrm{~K}$.
Hence, $U=31.89 \mathrm{~m} \mathrm{~s}^{-1}$ at $1 \mathrm{~B}$ over the mountain top is much stronger than $U=11.24 \mathrm{~m} \mathrm{~s}^{-1}$ at $1 \mathrm{~A}$ in the lower upstream region. The temperature at $1 \mathrm{C}, T_{\mathrm{C}}=272.30 \mathrm{~K}$ is also less than $T_{\mathrm{A}, \mathrm{B}}^{\mathrm{ad}}=T_{\mathrm{B}}-\beta_{\mathrm{ad}} \Delta z_{\mathrm{B}, \mathrm{C}}=274.56 \mathrm{~K}$, while $U=74.44 \mathrm{~m} \mathrm{~s}^{-1}$ at $1 \mathrm{C}$ is stronger than $U=31.89 \mathrm{~m} \mathrm{~s}^{-1}$ at $1 \mathrm{~B}$. Table 1 also shows the difference in $\mathrm{KE}$ between $1 \mathrm{~A}$ and $1 \mathrm{~B}, \mathrm{KE}_{\mathrm{B}}-\mathrm{KE}_{\mathrm{A}}=445.7 \mathrm{~m}^{2} \mathrm{~s}^{-2}$, and the difference in enthalpy $c_{p}\left(T_{\mathrm{A}, \mathrm{B}}^{\mathrm{ad}}-T_{\mathrm{B}}\right)=487.9 \mathrm{~m}^{2} \mathrm{~s}^{-2}$ at $1 \mathrm{~B}$. The difference of kinetic energy between $1 \mathrm{~B}$ and $1 \mathrm{C}$ is $2263 \mathrm{~m}^{2} \mathrm{~s}^{-2}$ and $c_{p}\left(T_{\mathrm{B}, \mathrm{C}}^{\mathrm{ad}}-T_{\mathrm{C}}\right)$ is $2272 \mathrm{~m}^{2} \mathrm{~s}^{-2}$ at $1 \mathrm{C}$, in good agreement with Eq. (16). Fig. 1a and Table 1 also show that the severe downslope winds on the lee side originate from $z \approx 1.1 \mathrm{~km}$ instead of from mid-level (4$6 \mathrm{~km}$ ) at $x \approx 160 \mathrm{~km}$, because the increase of $U$ depends on the change of enthalpy, $c_{p}\left(T_{i, f}^{\mathrm{ad}}-T_{f}\right)$, instead of $g \Delta z$.

Notably, the wind is relatively weak over the warm spot at $1 \mathrm{D}(x=347 \mathrm{~km}, z=1087 \mathrm{~m})$ where $B=$ $309,930 \mathrm{~m}^{2} \mathrm{~s}^{-2}, \theta=325.197 \mathrm{~K}, T=297.29 \mathrm{~K}$, and $U=$ $36.9 \mathrm{~m} \mathrm{~s}^{-1}$ as shown in row $1 \mathrm{D}$ of Table 1 and Fig. $1 \mathrm{~b}$. This warm spot with a weak wind is created by adiabatic subsidence warming, associated with a large descent from the mid-atmosphere. By contrast, the velocity in an incompressible fluid would be greater with increasing drop height.

Rows of $1 A^{*}$ and $B *$ in Table 1 show that the parcel with $B=276,007 \mathrm{~m}^{2} \mathrm{~s}^{-2}, \theta=286.9 \mathrm{~K}, T=272.24 \mathrm{~K}$, and $U=10.39 \mathrm{~m} \mathrm{~s}^{-1}$ from the inflow region at $1 \mathrm{~A}^{*}(x=$ $160 \mathrm{~km}, z=253.9 \mathrm{~m})$ moves to the mountain top $1 \mathrm{~B}^{*}$ $(x=320 \mathrm{~km}, z=2061 \mathrm{~m})$ with $B=276,007 \mathrm{~m}^{2} \mathrm{~s}^{-2}, \theta=$ 286. $9 \mathrm{~K}, T=254.36 \mathrm{~K}$, and $U=24.41 \mathrm{~m} \mathrm{~s}^{-1}$. The potential temperature $\theta$ remains almost constant along $B=$ $276,007 \mathrm{~m}^{2} \mathrm{~s}^{-2}$. The wind at $1 \mathrm{~B}^{*}$ is much stronger than that at $1 \mathrm{~A}^{*}$ while the pressure and temperature are lower than the environment as shown in Fig. 1b. The simulated temperature at $1 \mathrm{~B}^{*}, T_{1 \mathrm{~B}^{*}}=254.36 \mathrm{~K}$, is lower than. $T_{\mathrm{A}^{*} \mathrm{~B}}^{\mathrm{ad}}=T_{\mathrm{A}^{*}-} \beta_{\mathrm{ad}} \Delta z_{\mathrm{A}^{*}, \mathrm{~B}^{*}}=254.60 \mathrm{~K}$. The KE difference between $1 \mathrm{~A}^{*}$ and $1 \mathrm{~B}^{*}$ is $244.1 \mathrm{~m}^{2} \mathrm{~s}^{-2}$ and is also very close to $c_{p}\left(T_{\mathrm{A}^{*}, \mathrm{~B}^{*}}^{\mathrm{ad}}-T_{\mathrm{B}^{*}}\right)=250.0 \mathrm{~m}^{2} \mathrm{~s}^{-2}$ at $1 \mathrm{~B}^{*}$ according to Eq. (16).

Along $B=280,000 \mathrm{~m}^{2} \mathrm{~s}^{-2}$ at $1 \mathrm{~A}, 1 \mathrm{~B}$, and $1 \mathrm{C}, \theta$ remains around $291.1 \mathrm{~K}$, but the density changes considerably following the motion (i.e., $d \rho / d t \neq 0$ ); density also changes noticeably but $\theta$ remains near $286.9 \mathrm{~K}$ along $B=276,007 \mathrm{~m}^{2} \mathrm{~s}^{-2}$ at $1 \mathrm{~A}^{*}$ and $\mathrm{B}^{*}$. This differs significantly from $d \rho / d t=0$, as proposed by L53, or the constant density case of S85. The atmosphere used in L53 or S85 does not allow the parcel to depart from hydrostatic equation during its adiabatic motions. The stronger the acceleration, the larger it departs from hydrostatic equilibrium, since $\frac{d w}{d t}=-\frac{\partial p^{\prime}}{\rho \partial z}-g \frac{\rho^{\prime}}{\rho}$. 


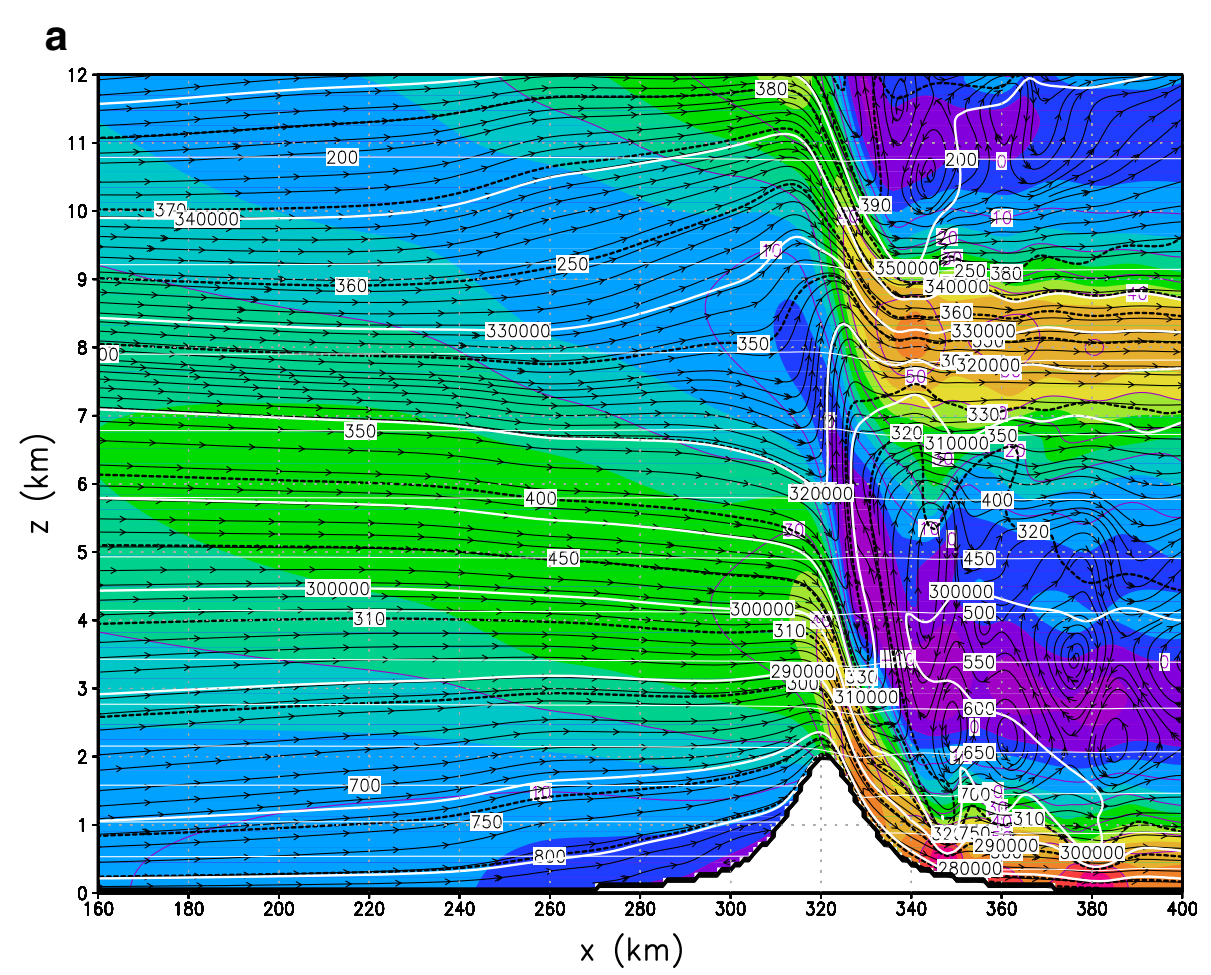

b

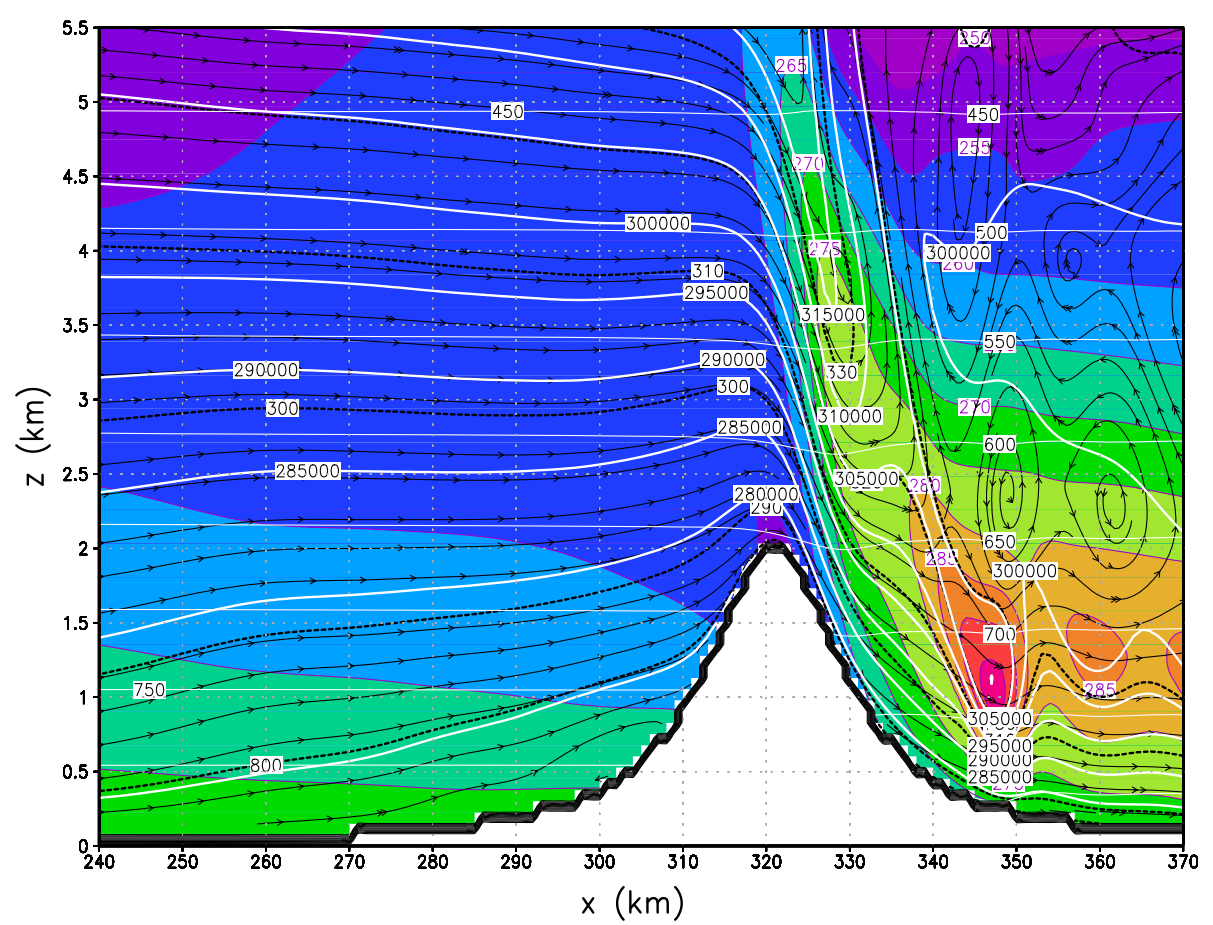

Fig. 1 a Simulated U (shaded color), B (thick white lines), $\theta$ (dashed black lines), $p$ (thin white lines), and streamlines at $t=6 \mathrm{~h}$ integration for case 1 . b Same as Fig. 1a except that the shaded color represents temperature $T$

The wind of a compressible air parcel can increase while the parcel rises with a cooling rate larger than adiabatic lapse rate. It means that extra-compressibility beyond the compression/expansion of hydrostatic-adiabatic process is crucial to the change of $\mathrm{KE}$ in the real atmosphere. The conventional Froude number only considers the 
conversion between the kinetic energy and potential energy as discussed in Eqs. (19) and (20) and is not definitive in the real atmosphere.

As discussed in Sun (2013), the zone of the weak (or reverse) winds in the mid-level $(5 \mathrm{~km} \sim 10 \mathrm{~km})$ creates a new blocking as an artificial steep mountain for the westerly flow in $z=7 \sim 8 \mathrm{~km}$. The flow moves over and creates strong winds on the lee side of this blocking. Combining a strong wind passing over the zone of weak-wind barrier and that exiting from the upper part of the hydraulic jump, the westerly wind reaches more than $60 \mathrm{~m} \mathrm{~s}^{-1}$ in $z \sim 8.2 \mathrm{~km}$ and $x \sim 340 \mathrm{~km}$. We can also see that the wind comes from $z \leq 8.2 \mathrm{~km}$ from the west and from the lower layer through the hydrostatic jump. Therefore, the increase of kinetic energy does not come from the conversion of potential energy, as discussed previously. The slanting strips of strong and weak (or reverse) westerly winds in $z>10 \mathrm{~km}$ resemble the propagating mountain waves. Because the air density decreases with height, the amplitude of mountain waves increase with height in the upper layer.

Case 2: Observed $x$-component wind and temperature of 11 January 1972 in Boulder are used at $x=0$.

This case has been studied intensively, as discussed in Sun (2013) and papers quoted in Background and in Klemp and Lilly (1975), Lilly (1978), Clark and Peltier
(1984), Durran (1986), Doyle et al. (2000), Hsu and Sun (2001), Sun and Hsu (2005), Lin (2007), etc. Fig. 2a, b shows the observed wind and potential temperature as functions of height at the inflow region. The shaded colors in Fig. 3a, b, c show the simulated wind, temperature, and density, respectively, at $t=6 \mathrm{~h}$. The contours of $B$ (thick white line), $\theta$ (dashed black lines), and the streamlines are almost parallel before the flow becomes turbulent, similar to case 1 . Bernoulli $B=279,890 \mathrm{~m}^{2} \mathrm{~s}^{-2}$ at $2 \mathrm{C}(x=340 \mathrm{~km}$, $z=562.3 \mathrm{~m})$, the location of a severe downslope wind on the lee side, where $U=65.61 \mathrm{~m} \mathrm{~s}^{-1}, \theta=291.3 \mathrm{~K}$, $T=271.01 \mathrm{~K}$, and $\rho=0.9987 \mathrm{~kg} \mathrm{~m}^{-3}$. The contour $B=279,890 \mathrm{~m}^{2} \mathrm{~s}^{-2}$ can be traced back to $2 \mathrm{~B}(x=320 \mathrm{~km}$, $z=2227 \mathrm{~m}$ ) over the mountain peak, where $U=22.94 \mathrm{~m} \mathrm{~s}^{-1}$, $\theta=291.3 \mathrm{~K}, T=256.65 \mathrm{~K}$, and $\rho=0.8715 \mathrm{~kg} \mathrm{~m}^{-3}$, and $2 \mathrm{~A}(x=160 \mathrm{~km}, z=1123 \mathrm{~m})$ in the upstream where $U=4.037 \mathrm{~m} \mathrm{~s}^{-1}, \theta=291.3 \mathrm{~K}, T=267.67 \mathrm{~K}$, and $\rho=$ $0.9685 \mathrm{~kg} \mathrm{~m}^{-3}$. Rows $2 \mathrm{~A}, 2 \mathrm{~B}$, and $2 \mathrm{C}$ in Table 1 show that the temperature at $2 \mathrm{~B}, T_{\mathrm{B}}=256.65 \mathrm{~K}$, is cooler than $T_{\mathrm{A}, \mathrm{B}}^{\mathrm{ad}}=256.90 \mathrm{~K}$, and $T_{\mathrm{C}}=271.01 \mathrm{~K}$ is less than $T_{\mathrm{B}, \mathrm{C}}^{\mathrm{ad}}=$ $272.90 \mathrm{~K}$ at $2 \mathrm{C}$. The large increase in $\mathrm{KE}$ between $2 \mathrm{~B}$ and $2 \mathrm{C}\left(\mathrm{KE}_{\mathrm{C}}-\mathrm{KE}_{\mathrm{B}}=1892 \mathrm{~m}^{2} \mathrm{~s}^{-2}\right)$ is consistent with $c_{p}\left(T_{\mathrm{B}, \mathrm{C}}^{\mathrm{ad}}-T_{\mathrm{C}}\right)=1898.0 \mathrm{~m}^{2} \mathrm{~s}^{-2}$ due to a large cooling $(1.89 \mathrm{~K})$ of the air parcel while it ascends/descends adiabatically. It is noted that the extra cooling also accompanies the
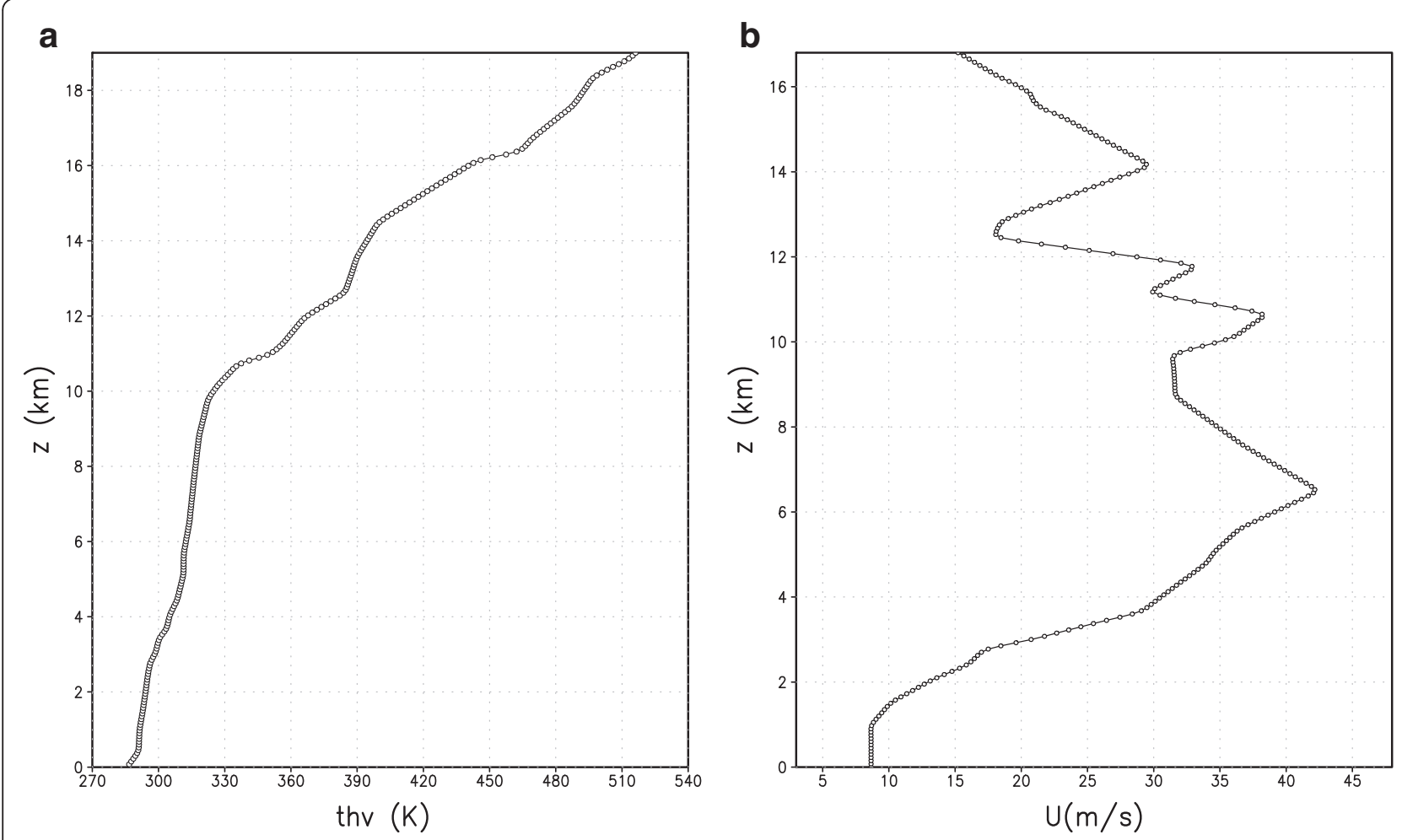

Fig. 2 a $\theta(z)$ at inflow for case 2. $\mathbf{b} \cup(z)$ at inflow for case 2 

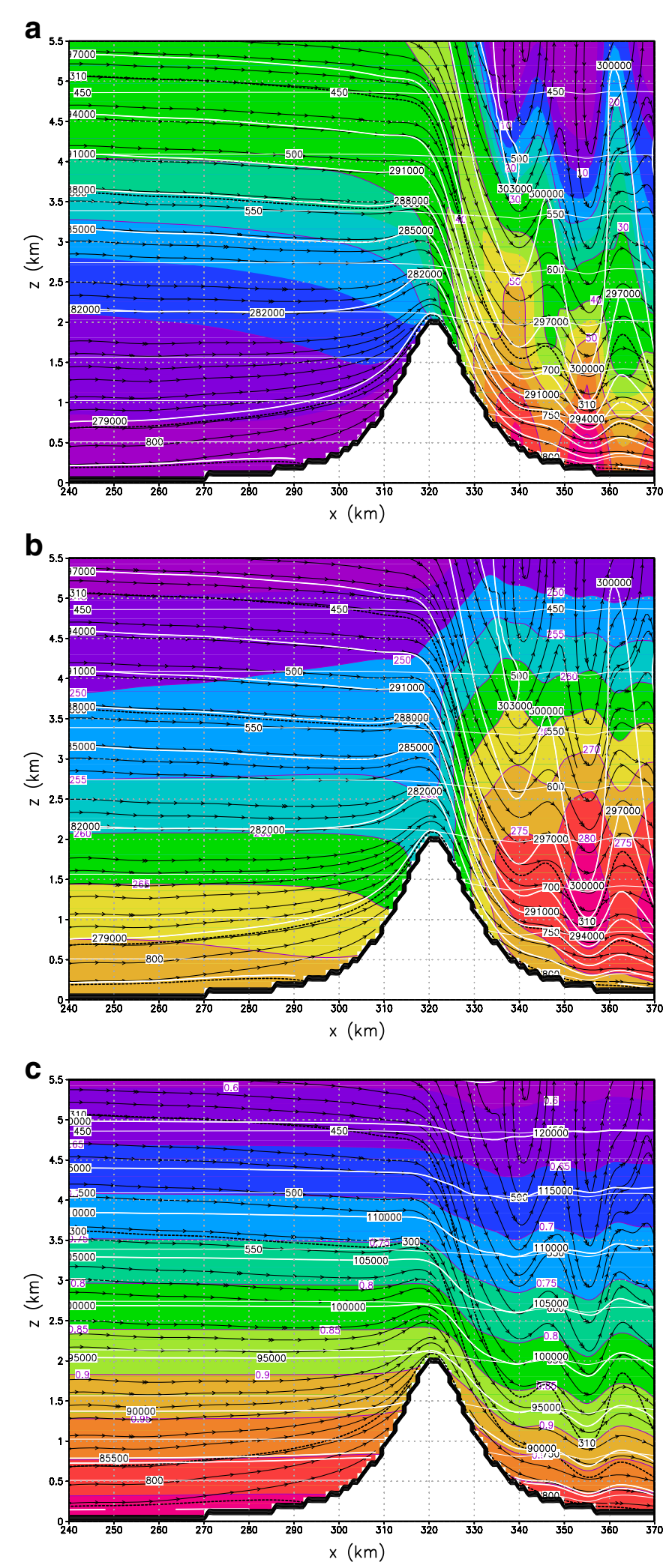

Fig. 3 a Same as Fig. 1a except for case 2. b Same as Fig. 1b except for case 2. c $\rho$ (shaded color), $\theta$ (dashed black lines), $p$ (thin white lines), streamlines, and $B_{\mathrm{L}}$ (thick white lines), based on $\rho_{i}$ in Eq. (11a) at $t=6 \mathrm{~h}$ for case 2 
pressure and density decreases compared to hydrostaticadiabatic process in the area of severe downslope wind on the lee side (Fig. 2a, b).

We can also identify the properties of the air parcel originating at $2 \mathrm{~A}^{*}(x=160 \mathrm{~km}, z=582.9 \mathrm{~m})$ with $B=$ $278,039 \mathrm{~m}^{2} \mathrm{~s}^{-2}, \theta=289.3 \mathrm{~K}, T=271.10 \mathrm{~K}$, and $U=$ $2.18 \mathrm{~m} \mathrm{~s}^{-1}$, which reaches the mountain top at $2 \mathrm{~B}^{*}$ $(x=320 \mathrm{~km}, z=2061 . \mathrm{m})$, where $B=278,039 \mathrm{~m}^{2} \mathrm{~s}^{-2}, \theta=$ $289.3 \mathrm{~K}, T=256.52 \mathrm{~K}$, and $U=18.22 \mathrm{~m} \mathrm{~s}^{-1}$. Again, $c_{p}\left(T_{\mathrm{A}^{*}, \mathrm{~B}^{*}}^{\mathrm{ad}}-T_{\mathrm{B}^{*}}\right)=155.6 \mathrm{~m}^{2} \mathrm{~s}^{-2}$ is also close to $\mathrm{KE}_{\mathrm{B}^{*}}-$ $\mathrm{KE}_{\mathrm{A}^{*}}=163.7 \mathrm{~m}^{2} \mathrm{~s}^{-2}$ shown in the rows of $2 \mathrm{~A}^{*}$ and $2 \mathrm{~B}^{*}$ of Table 1 . The situation is similar to the previous case, even though the temperature and wind at $x=0$ are heightdependent. Rows $2 \mathrm{~A}^{*}-2 \mathrm{~B}^{*}$ of Table 1 also show that $\theta$ remains nearly constant along a constant $B$-line, but the density changes considerably as discussed in case 1 .

It is also notable that the pressure of the parcel is lower than the surrounding pressure at the same height (Fig. 3a, b). The contour of $B=2,790,000 \mathrm{~m}^{2} \mathrm{~s}^{-2}$ (Fig. 3a, b) shows that a warm parcel with a weak wind in the lower layer in the upstream rises to the mountain top while its temperature decreases beyond adiabatic lapse rate and the wind increases. Fig. $3 \mathrm{a}, \mathrm{b}$ also shows that the region of strong downslope wind on the lee side is cooler than its surroundings. As discussed previously, the strong downslope wind originates from a relatively low level as in cases 1 and 2. The change of KE depends on $c_{p}\left(T_{i, f}^{\text {ad }}-T_{f}\right)$ instead of the vertical displacement of $g \Delta z$. The source region of downslope wind around $2 \mathrm{~km}$ (Fig. 3b) is higher than in case 1 because of a strong wind shear at $x=0$ in case 2 .

Figure 3c and Table 1 show that the contours of $\theta$ (dashed black lines), streamlines, $\rho$ (shaded color), and $B_{\mathrm{L}}$ (thick white line) based on $\rho=\rho_{i}(z, x=0, t=0)$ of Eq. (11a). The contours of $B_{\mathrm{L}}$ and density are parallel, but they intercept isentropic lines and streamlines near the mountain. This indicates that parcels at the mountain peak cannot follow a constant $B_{\mathrm{L}}$ to $2 \mathrm{C}(x=340 \mathrm{~km}$, $z=562.3 \mathrm{~m}$ ). Similarly, the contours of $B_{\mathrm{S}}$ based on a constant density $\left(\rho=1 \mathrm{~kg} \mathrm{~m}^{-3}\right)$ of Eq. (11b) also intercept constant isentropic lines and streamlines (not shown); therefore, a parcel cannot follow $B_{\mathrm{S}}$ lines either.

Case 3: At $x=0$, the observed $x$-component wind of 11 January 1972 in Boulder is used, but $\beta=3.5 \mathrm{~K} \mathrm{~km}^{-1}$ for $z<12 \mathrm{~km} ; \beta=0.7 \mathrm{~K} \mathrm{~km}^{-1}$ for $z>12 \mathrm{~km}$.

The simulated wind (shaded colors) at $t=6 \mathrm{~h}$ (Fig. 4) reveals that the downslope wind $\left(U=23.23 \mathrm{~m} \mathrm{~s}^{-1}\right)$ at $3 \mathrm{C}$ $(x=353 \mathrm{~km}, z=305.1 \mathrm{~m}$; row $3 \mathrm{C}$ in Table 1$)$ is much weaker than the $U=65.6 \mathrm{~m} \mathrm{~s}^{-1}$ of case 2 or $74 \mathrm{~m} \mathrm{~s}^{-1}$ of case 1. A stable stratification and a weak wind in the low layer cause the flow to move over the mountain in close to hydrostatic equilibrium (i.e., $d w / d t \approx 0$ ). At $3 \mathrm{~A}$ $(x=160 \mathrm{~km}, z=531.3 \mathrm{~m}), U=8.159 \mathrm{~m} \mathrm{~s}^{-1}$ is slightly less than $U=10.71 \mathrm{~m} \mathrm{~s}^{-1}$ at $3 \mathrm{~B}(x=320 \mathrm{~km}, z=2139 \mathrm{~m})$, and $T_{\mathrm{B}}=253.84 \mathrm{~K}$ is slightly less than $T_{\mathrm{A}, \mathrm{B}}^{\mathrm{ad}}=253.86 \mathrm{~K}$.

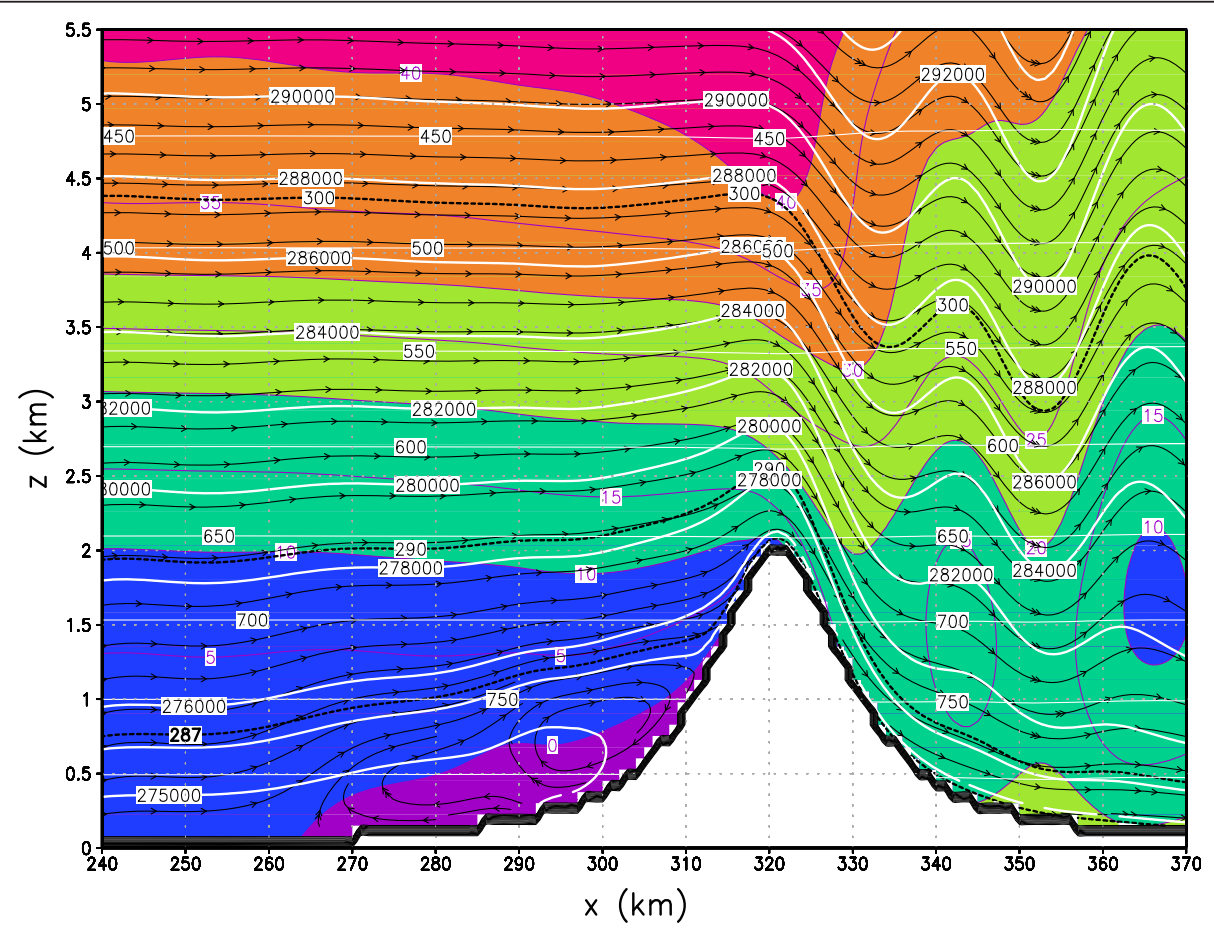

Fig. 4 Same as Fig. 1a except for case 3 
$\mathrm{KE}_{\mathrm{B}}-\mathrm{KE}_{\mathrm{A}}=24.16 \mathrm{~m}^{2} \mathrm{~s}^{-2}$ is very close to $c_{p}\left(T_{\mathrm{A}, \mathrm{B}}^{\mathrm{ad}}-T_{\mathrm{B}}\right)=$ $17.07 \mathrm{~m}^{2} \mathrm{~s}^{-2}$. The increase of $\mathrm{KE}$ at $3 \mathrm{~B}$ comes from the decrease of enthalpy. At $3 \mathrm{C}, T_{\mathrm{C}}=271.52 \mathrm{~K}$ is also slightly less than $T_{\mathrm{B}, \mathrm{C}}^{\mathrm{ad}}=271.74 \mathrm{~K}$, and $c_{p}\left(T_{\mathrm{B}, \mathrm{C}}^{\mathrm{ad}}-T_{\mathrm{C}}\right)=220.9 \mathrm{~m}^{2} \mathrm{~s}^{-2}$ is close to $\mathrm{KE}_{\mathrm{C}}-\mathrm{KE}_{\mathrm{B}}=212.5 \mathrm{~m}^{2} \mathrm{~s}^{-2}$. This is consistent with the Bernoulli equation and also confirms that if $T_{i, f}^{\text {ad }}=T_{i^{-}}$ $\beta_{\text {ad }} \Delta z \approx T_{f}$, we will have $\mathrm{KE}_{f} \approx \mathrm{KE}_{i}$.

Case 4. It is the same as case 2, except on a nonslip surface.

Since a free-slip surface is unrealistic, we examine the validity of the Bernoulli equation over a nonslip surface, which avoids the propagation of the hydraulic jump obtained on a free-slip surface. The simulated $\theta$ and $B$ lines at $t=6 \mathrm{~h}$ deform drastically due to the effect of surface friction (Fig. 5). However, $\theta$ and $B$ lines at $500 \mathrm{~m}$ or more above the ground are not affected by surface friction. Table 1 shows that the contour of $B=283,597 \mathrm{~m}^{2} \mathrm{~s}^{-2}$ comes from 4A $(x=160 \mathrm{~km}, z=2870 . \mathrm{m})$ with $U=$ $18.55 \mathrm{~m} \mathrm{~s}^{-1}$ and $\theta=295.7 \mathrm{~K}$ and reaches $4 \mathrm{~B}(x=320 \mathrm{~km}$, $z=3149 \mathrm{~m}$ ) over the mountain peak with $U=24.16 \mathrm{~m} \mathrm{~s}^{-1}$ and $\theta=295.7 \mathrm{~K}$. The change of kinetic energy, $\mathrm{KE}_{\mathrm{B}}-\mathrm{KE}_{\mathrm{A}}=$ $120.5 \mathrm{~m}^{2} \mathrm{~s}^{-2}$ is very close to $c_{p}\left(T_{\mathrm{A}, \mathrm{B}}^{\mathrm{ad}}-T_{\mathrm{B}}\right)=119.5 \mathrm{~m}^{2} \mathrm{~s}^{-2}$. After passing over the mountain peak, the flow descends and creates a strong downslope wind $U=38.19 \mathrm{~m} \mathrm{~s}^{-1}$ and $\theta=295.6 \mathrm{~K}$ at $4 \mathrm{C}(x=332 \mathrm{~km}, z=1087.08 \mathrm{~m}) . \mathrm{KE}_{\mathrm{C}}-$ $\mathrm{KE}_{\mathrm{B}}=446.7 \mathrm{~m}^{2} \mathrm{~s}^{-2}$ and $c_{p}\left(T_{\mathrm{B}, \mathrm{C}}^{\mathrm{ad}}-T_{\mathrm{C}}\right)=436.7 \mathrm{~m}^{2} \mathrm{~s}^{-2}$. These are in good agreement because they are derived from a very large value of $B\left(=283,597 \mathrm{~m}^{2} \mathrm{~s}^{-2}\right)$. Above the surface friction layer, lines of $\theta, B$, and streamlines are nearly parallel. The potential temperature is almost conserved along $B=283,597 \mathrm{~m}^{2} \mathrm{~s}^{-2}$ as well. The wind speed increases while the parcel moves over the mountain top at $x=320 \mathrm{~km}$, along $B=283,597 \mathrm{~m}^{2} \mathrm{~s}^{-2}$. However, the contours of $B \leq 281,000 \mathrm{~m}^{2} \mathrm{~s}^{-2}$ deform drastically when they approach the mountain. They are also quite irregular in the areas of high turbulence on the lee side, where the flow becomes unsteady. The strong downslope wind comes from a layer which is above the influence of surface friction. Overall, the downslope wind is much weaker than in case 2. As discussed in Sun (2013), the severe downslope wind can be enhanced and maintained by the convergence of the geostrophicunbalanced, northwesterly upper-level-jet due to geostrophic adjustment. The simulated wind here is much weaker than those in Sun (2013), because neither the Coriolis force nor the geostrophic-unbalanced upper-level jet is included here. For more details, the reader is referred to Sun (2013).

\section{Conclusions}

The Bernoulli equation is applied to an air parcel that originates from a low level at the inflow region, speeds up as it moves adiabatically over a mountain, then

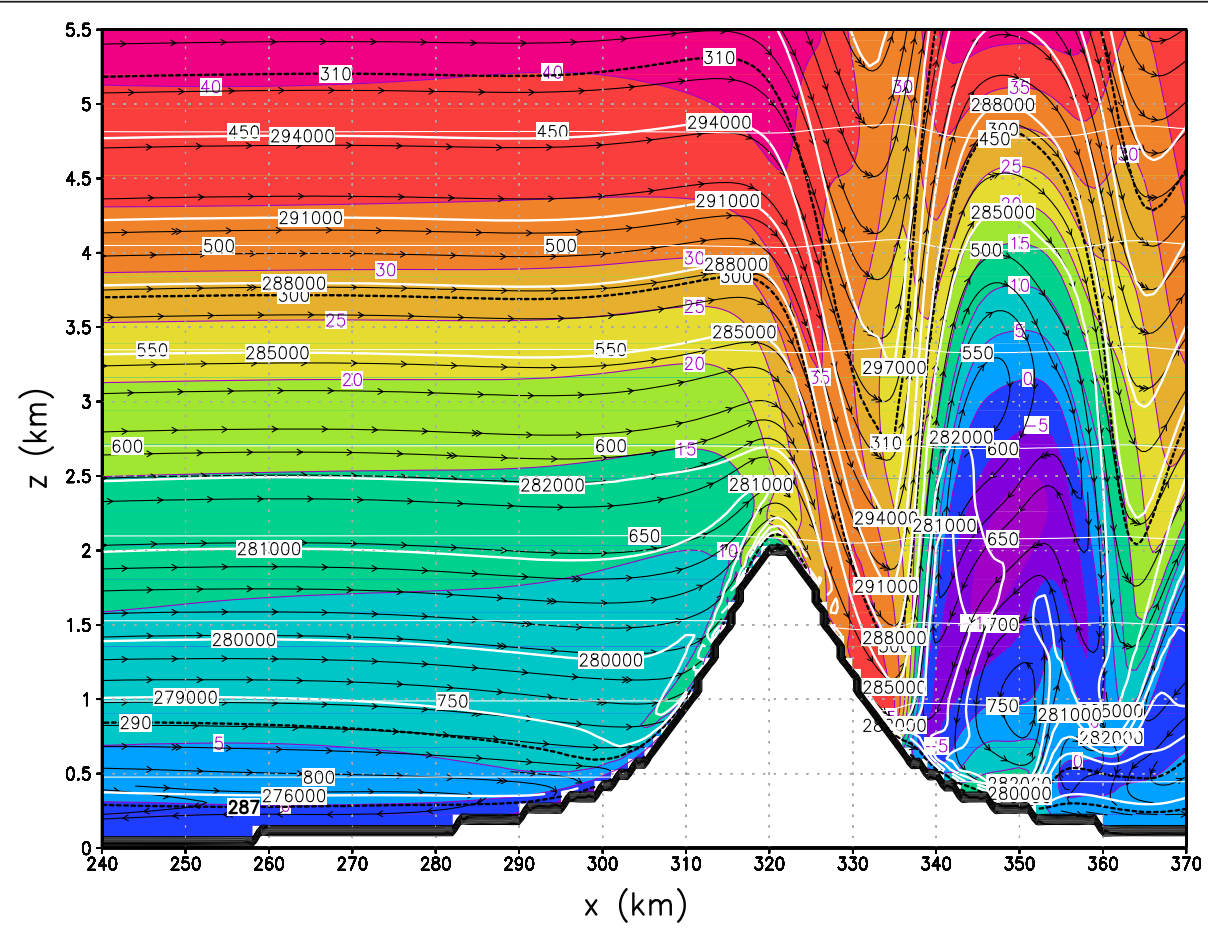

Fig. 5 Same as Fig. 1a except for case 4 
descends on the lee side and forms a strong downslope wind. Excess compressibility of the atmosphere beyond hydrostatic-adiabatic process allows the air parcel to depart from hydrostatic equilibrium, resulting in a change in kinetic energy (i.e., wind speed) which comes from changes in enthalpy. Numerical simulations confirm that potential temperature remains almost constant but temperature, density, and pressure vary considerably along constant Bernoulli lines. The mechanism described here does not appear in the incompressible, quasi-hydrostatic fluids used by L53 or S85. The results also suggest that the conventional Froude number, defined as the ratio of kinetic energy to the potential energy in the atmosphere, is not a good indicator for determining whether an air parcel can move over a mountain, except if the vertical motion is weak and the process is near hydrostatic equilibrium.

\section{Competing interests}

The authors declare that they have no competing interests.

\section{Authors' contributions}

The senior author, WY Sun developed and run the nonlinear model. Both authors worked on theoretical analyses and analyzed model simulations. Both authors read and approved the final manuscript.

\section{Acknowledgements}

We sincerely thank Prof. Y. L. Lin for the many useful comments and the reviewers for their comments, as well as Drs. W. R. Hsu, M. Shieh, B. MacCall, T. Oh, and S. H. Chen for their contributions to the development of the National Taiwan University-Purdue University nonhydrostatic model. The computing facilities provided by Purdue University are also appreciated.

\section{Author details}

${ }^{1}$ Department of Earth, Atmospheric and Planetary Sciences, Purdue University, 550 Stadium Mall Drive, West Lafayette, IN 47907-2051, USA. ${ }^{2}$ Department of Atmospheric Sciences, National Central University, Chung-Li, Tao-yuan 320, Taiwan. ${ }^{3}$ Hydrospheric Atmospheric Research Center (HyARC), Nagoya University, Nagoya 464-8601, Japan. ${ }^{4}$ Woods Hole Oceanographic Institution, Woods Hole, MA 02543-1050, USA. ${ }^{5}$ Present address: Naval Undersea Warfare Center, Newport, RI 02841-1708, USA.

Received: 30 December 2014 Accepted: 10 April 2015

Published online: 09 June 2015

\section{References}

Aihara M, Hirasawa M (1988) On severe downslope wind due to the mountain wave-induced critical level. Pap Meteorol Geophys 39:59-77

Baines PG (1995) Topographic Effects in Stratified Flows. Cambridge University Press, New York, 489pp.

Clancy $\sqcup$ (1975) Aerodynamics. Wiley, New York, 610pp

Clark TL, Peltier WR (1977) On the evolution and stability of finite amplitude mountain waves. J Atoms Sci 34:1715-1730

Clark TL, Peltier WR (1984) Critical level reflection and the resonant growth of nonlinear mountain waves. J Atmos Sci 41:3122-3134

Doyle JD, Durran DR, Chen C, Colle BA, Georgelin M, Grubisic V, Hsu WR, Huang CY, Landau D, Lin YL, Poulos GS, Sun WY, Weber DB, Wurtele MG, Xue M (2000) An intercomparison of model predicted wave breaking for the 11 January 1972 Boulder windstorm. Mon Weather Rev 128:901-914

Durran DR (1986) Another look at downslope windstorms. Part l: the development of analogs of supercritical flow in an infinitely deep, continuously stratified fluid. J Atmos Sci 43:2527-2543

Gill AE (1982) Atmosphere-ocean dynamics. Academic, New York, 662 pp

Hsu WR, Sun WY (2001) A time-split, forward-backward numerical model for solving a nonhydrostatic and compressible system of equations. Tellus A 53:279-299
Klemp JB, Lilly DK (1975) The dynamics of wave-induced downslope winds. J Atmos Sci 32:320-339

Lilly DK (1978) A severe downslope windstorm and aircraft turbulence induced by a mountain wave. J Atmos Sci 35:59-77

Lin YL (2007) Mesoscale dynamics. Cambridge University Press, NY, 630pp

Long RR (1953) (L53). Some aspects of the flow of stratified fluids. Part I. A theoretical investigation. Tellus A 5:42-58

Peltier WR, Clark TL (1979) The evolution and stability of finite-amplitude mountain waves. Part II: Surface drag and severe downslope windstorms. J Atmos Sci 36:1498-1529

Queney P (1948) The problem of airflow over mountains: a summary of theoretical studies. Bull Am Meteorol Soc 29:16-26

Smith RB (1985) (S85) On severe downslope winds. J Atmos Sci 42:2597-2603

Smith RB (1989) Hydrostatic airflow over mountains. Adv. Geophys. 31, 1-41. [http://www.yale.edu/ceo/Test/1989_Advances.pdf]

Sun WY (2013) Numerical study of severe downslope windstorm. Weather Climate Extremes 2:22-30

Sun WY, Hsu WR (2005) Effect of surface friction on downslope wind and mountain waves. Terr Atmos Ocean Sci 16:393-418

Sun WY, Sun OM, and Tsuboki K (2012) A modified atmospheric nonhydrostatic model on low aspect ratio grids. Tellus A 2012, 64, 17516, http://dx.doi.org/ 10.3402/tellusa.v64i0.17516

Sun WY, Yang KJ-S, Lin NH (2013a) Numerical simulations of Asian dust-aerosols and regional impacts on weather and climate-part I: control case-PRCM simulation without dust-aerosols. Aerosol Air Quality Res 13:1630-1640. doi:10.4209/aaqr.2013.06.0207

Sun WY, Yang KJ-S, Lin N-H (2013b) Numerical simulations of Asian dust-aerosols and regional impacts on weather and climate-part II: PRCM-dust model simulation. Aerosol Air Quality Res 13:1641-1654. doi:10.4209/aaqr.2013.06.0208

Sun WY, Sun OM, and Tsuboki K (2013c) A modified atmospheric nonhydrostatic model on low aspect ratio grids-part II. Tellus A 2013, 65, 19681, http://dx.doi.org/10.3402/tellusa.v65i0.19681.

\section{Submit your manuscript to a SpringerOpen ${ }^{\circ}$ journal and benefit from:}

- Convenient online submission

- Rigorous peer review

- Immediate publication on acceptance

- Open access: articles freely available online

- High visibility within the field

- Retaining the copyright to your article

Submit your next manuscript at $>$ springeropen.com 